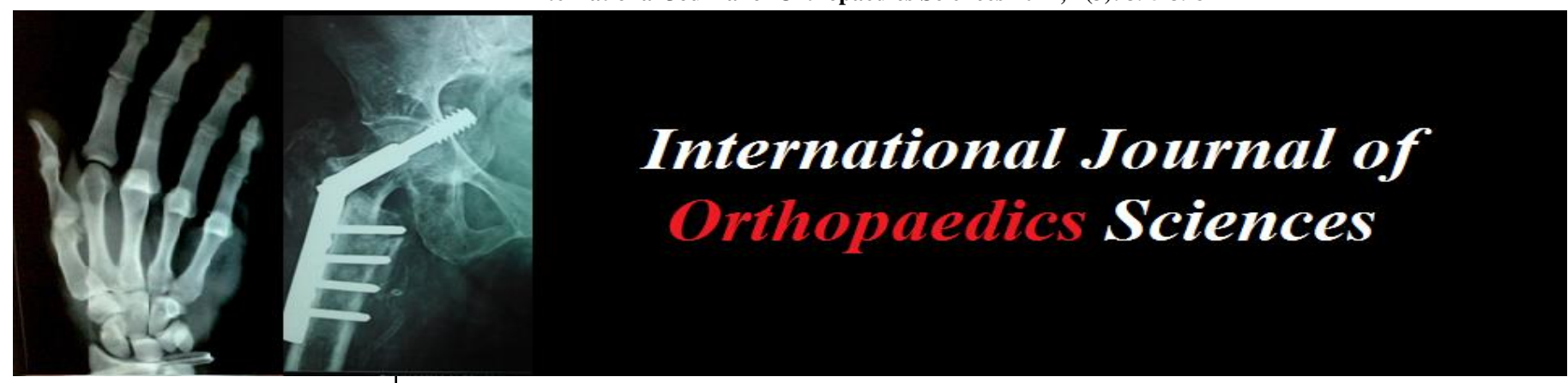

E-ISSN: 2395-1958

P-ISSN: 2706-6630

IJOS 2021; 7(3): 395-398

(C) 2021 IJOS

www.orthopaper.com

Received: 19-05-2021

Accepted: 21-06-2021

Dr. Gurram Venkata Siva Naga Raja

Assistant Professor,

Department of Orthopaedics,

Konaseema Institute of Medical

Science, Amalapuram,

Andhra Pradesh, India

Dr. Ram Bhupal Varma R

Assistant Professor,

Department of Orthopaedics,

Konaseema Institute of Medical

Science, Amalapuram,

Andhra Pradesh, India
Corresponding Author: Dr. Ram Bhupal Varma R Assistant Professor, Department of Orthopaedics, Konaseema Institute of Medical

Science, Amalapuram,

Andhra Pradesh, India

\section{A prospective comparative evaluation of outcome of surgical management of unstable comminuted fracture of distal radius using external and internal fixation}

\author{
Dr. Gurram Venkata Siva Naga Raja and Dr. Ram Bhupal Varma $R$
}

DOI: https://doi.org/10.22271/ortho.2021.v7.i3f.2778

Abstract

Background: The goal of treatment of distal fracture of radius is restoration of normal function and prevention of complication like malunion, joint stiffness, and deformity but achievement of desired outcome is always a challenge in fracture of distal end of radius. As there is variability in the conclusion of various literature present study has been conducted to evaluation of outcome of surgical management of unstable comminuted fracture of distal radius using external and internal fixation in our clinical conditions.

Method: Patients with unstable comminuted fracture of distal radius admitted in the department of orthopaedics and trauma are enrolled for this study based on inclusion and inclusion criteria. For functional assessment of outcome, we used DASH (Disability of the Arm, shoulder and hand) Method.

Result: The mean of DASH score was16.24 \pm 4.62 in external fixation group and $14.65 \pm 3.98$ in internal fixation group. Both groups are comparable to each other as it is not statistically significant $(\mathrm{P}>.05)$. There is no incidence of compressive neuropathy, Sudeck's osteodystrophy, iatrogenic rupture and nerve injury.

Discussion: From present study we can conclude that fracture of distal end of radius is common fracture with male predominance. Injury is more common on right side and fall from height is common mode of injury. DASH score was less in internal fixation group. Post-operative infection was high in infernal fixation group. Functional outcome was better in outcome was better in internal fixation group.

Keywords: fracture distal radius, internal fixation, external fixation, DASH score

\section{Introduction}

Distal end of radius is widest part and four sided in section includes the metaphyseal and epiphyseal regions. Fracture of distal end of radius is most common fracture in adult responsible for $8 \%-15 \%$ of all bony injuries in adults and was first described by Dr. A Collis in 1814 in Edinburgh journal of medicine in that he has concluded that he considered this as by far the most common injury to which the wrist or carpal extremities of the radius and ulna are exposed ${ }^{[1,2]}$. Associated osteoporosis makes it more complicated and increases mortality and morbidity. The goal of treatment of distal fracture of radius is restoration of normal function and prevention of complication like malunion, joint stiffness, and deformity but achievement of desired outcome is always a challenge in fracture of distal end of radius. Various options are available for the treatment of fracture of distal end of radius. Closed reduction and casting is used for minor comminution, without or with minimal displacements but associated with malunion and stiffness of joint. External fixation is considered superior to plaster immobilization in the young patients with an intra-articular comminuted fracture of the distal radius. Open reduction and internal fixation is considered recent advances in treatment of distal radius fractures is the more frequent application of open reduction and internal fixation, especially for intra-articular fractures ${ }^{[3,4,5]}$.

Various studies have been conducted regarding outcome of external fixation versus internal fixation of comminuted fracture of distal radius. Wei DH, Poolman RW, Bhandari M, Wolfe VM, Rosenwasser MP et al. has reported that for surgical fixation of unstable distal radius fractures, ORIF yields significantly better functional outcomes, forearm supination, and restoration of anatomic volar tilt. However, external fixation results in better grip strength, 
wrist flexion, and remains a viable surgical alternative ${ }^{[6]}$. Wang J, Yang Y, Ma J, Xing D, Zhu S et al. has reported that EF (external fixation) results in higher incidence of infection compared to ORIF (open reduction and internal fixation). ORIF is equal to EF for either grip strength, or range of motion of the injured wrist, or incidence of malunion or median nerve dysfunction at the end of the follow-up period [7].

As there is variability in the conclusion of various literature present study has been conducted to evaluation of outcome of surgical management of unstable comminuted fracture of distal radius using external and internal fixation in our clinical conditions.

\section{Material and Method}

This is a prospective non randomized observational study conducted in the department of orthopaedics Konaseema institute of medical science from March 2017 to May 2021.

Selection of patients: - Patients with unstable comminuted fracture of distal radius admitted in the department of orthopaedics and trauma are enrolled for this study based on inclusion and inclusion criteria.

\section{Inclusion criteria: Exclusion criteria}

\section{Age above 18 years: Pathological fracture}

Both sexes: Compound fracture unstable Comminuted fracture of distal radius

Sample size: Based on exclusion and inclusion criteria 80 patients were enrolled during four years of this study and divided in to two groups have 40 patients each, one group were treated with external fixation and another treated with internal fixation.

Ethics: Present study is approved by institutional ethics committee. A written informed consent was obtained from all patients before enrolling them for study.

Collection of data: All detail of the patient was recorded in predesigned Performa. After discharge from hospital patient was followed regularly both clinically and radiologically till full recovery.

\section{Method}

After admission in pre-operative planning, all basic investigation was done associated injuries were evaluated and treated. Evaluation of fracture was done and patients were non randomly selected for treated either external fixation or OIRF decided by senior faculty of that unit. Regarding internal fixation of based on choice of anaesthetics and patient's condition regional block or general anaesthesia was given. Under all ascetic condition longitudinal incision was given. Fracture was reduced and buttress plate was moulded in such a way that it will fix to the proximal fragment, the distal transverse part will act as a buttress and hold the fractures reduced. Screw was inserted in to the fracture part of fragment through the distal part of plate. Restoration of articular surface and reduction of articular surface was confirmed by AP and lateral view by C- arm. Position of muscle was restored and wound was closed.

For external fixation based on choice of anaesthetics and patient's condition regional block or general anaesthesia was given. After shifting patients in the operation theatre external fixator was applied. For radius $3.5 \mathrm{~mm}$ Schanz type and for metacarpal $2.5 \mathrm{~mm}$ schanz type pin was used in all patients. Both pins were fixed as per standard protocol to radius and metacarpal bone and were connected by two external rods. Reduction was achieved under image intensifier, angular element of deformity was controlled and positioned is ulnar deviation of forearm.

Upper limb was elevated and monitored for neurovascular complication for 24 hours. Patients were encouraged to move finger, elbow and shoulder. Patients were discharged and followed at 2-week interval up to 6 weeks, then every 3 months till one year. Patients were examined for abnormal mobility of the distal radioulnar joint, deformity, measurement of range of movements extending from shoulder to digits tenderness, grip strength, light touch and pin prick sensitivity.

Both group of patients during the follow up period, were advised about the exercises of the elbow, digits, and shoulder. External fixation patients were advised about cleaning of external fixator. Fixator was removed after clinical and radiological evidence of fracture healing after that a removable splint or POP slab was given for another 3-6 weeks.

For functional assessment of outcome, we used DASH (Disability of the Arm, shoulder and hand) Method ${ }^{[9]}$.

Statistical analysis: Data were recorded in excel sheet and statistical Analysis was done with software SPSS-14 version. Qualitative data were calculated as percentage and proportions. Quantitative data were expressed as mean \pm SD. Chi square test and unpaired t test were used form analysis of data and $\mathrm{P}$ value less than .05 considered statistically significant.

\section{Result}

During study period of four years, we enrolled 80 patients as per selection criteria and divided in to two groups have 40 patients each, one group were treated with external fixation and another treated with internal fixation.

Table 1: Clinicodemographic profile of patients with comminuted fracture of distal radius

\begin{tabular}{|c|c|c|c|c|}
\hline \multicolumn{2}{|c|}{ Variable } & External fixation & Internal fixation & P value \\
\hline \multicolumn{2}{|c|}{ Age (years) } & $41.35 \pm 12.38$ & $40.15 \pm 11.55$ & .32 \\
\hline \multirow{2}{*}{ Sex } & Male & 26 & 25 & \multirow{2}{*}{.818} \\
\hline & Female & 14 & 15 & \\
\hline \multirow{2}{*}{ Side of fracture } & Right & 28 & 30 & \multirow{2}{*}{.616} \\
\hline & Left & 12 & 10 & \\
\hline \multirow{3}{*}{ Mode of injury } & RTA & 12 & 10 & \multirow{3}{*}{.87} \\
\hline & Fall from height & 20 & 22 & \\
\hline & Trivial fall & 8 & 8 & \\
\hline \multirow{2}{*}{ Type of fracture } & Closed & 28 & 26 & \\
\hline & open & 2 & 4 & \\
\hline \multicolumn{2}{|c|}{ Dash score } & $16.24 \pm 4.62$ & $14.65 \pm 3.98$ & .07 \\
\hline
\end{tabular}


As per table 1, mean age of patients were $41.35 \pm 12.38$ years in external fixation and $40.15 \pm 11.55$ years in internal fixation group. Both groups are comparable to each other as it is not statistically significant $(\mathrm{P}>.05)$. in external fixation group there were 26 male and 14 female, in internal fixation group there were 25 male and 15 female. Both groups are comparable to each other with respect to sex distribution as $\mathrm{p}$ value is .818. Regarding mode of injury in external fixation group RTA was cause of injury in 12 patients, fall from height was present in 20 patients and trivial fall was mode of injury in 8 patients similarly in internal fixation group RTA was cause of injury in 10 patients, fall from height was present in
22 patients and trivial fall was mode of injury in 8 patients. Both groups are comparable to each other with respect to sex distribution as $\mathrm{p}$ value is .61. Regarding type of fracture in external fixation group 28 patients have closed fracture and 2 patients have open fracture similarly in internal fixation group 26 patients have closed fracture and 4 patients have open fracture. Both groups are comparable to each other with respect to sex distribution as $\mathrm{p}$ value is .87 . The mean of DASH score was $16.24 \pm 4.62$ in external fixation group and $14.65 \pm 3.98$ in internal fixation group. Both groups are comparable to each other as it is not statistically significant $(\mathrm{P}>.05)$.

Table 2: Complication associated with external and internal fixation

\begin{tabular}{|c|c|c|}
\hline Variable & External fixation & Internal fixation \\
\hline Joint stiffness & 1 & 1 \\
\hline Infection & 5 & 1 \\
\hline Compressive neuropathy & 0 & 0 \\
\hline Sudeck's osteodystrophy & 0 & 0 \\
\hline Iatrogenic rupture & 0 & 0 \\
\hline Nerve injury & 0 & 0 \\
\hline Finger stiffness & 1 & 0 \\
\hline
\end{tabular}

Regarding complication in post-operative period in both group one patient has joint stiffness and one have finger stiffness and five patients have infection. In internal fixation group one patient have joint stiffness and one patient have infection. There is no incidence of compressive neuropathy, Sudeck's osteodystrophy, iatrogenic rupture and nerve injury.

Table 3: Functional outcome of patient was assessed using DASH (Disability of the Arm, shoulder and hand) Method.

\begin{tabular}{|c|c|c|c|}
\hline Functional result & External fixation & Internal fixation & P value \\
\hline Excellent & 12 & 20 & \multirow{2}{*}{.26} \\
\hline Good & 18 & 15 & \\
\hline Fair & 8 & 4 & \\
\hline poor & 2 & 1 & \\
\hline
\end{tabular}

Functional outcome of patient was assessed using DASH (Disability of the Arm, shoulder and hand) Method was excellent in 12 patients, good in 18 patients, fair in 8 patients and poor in 2 patients in external fixation group. Similarly, the functional outcome was excellent in 20 patients, good in 15 patients, fair in 4 patients and poor in 1 patient in internal fixation group Both groups are comparable to each other as it is not statistically significant $(\mathrm{P}>.05)$.
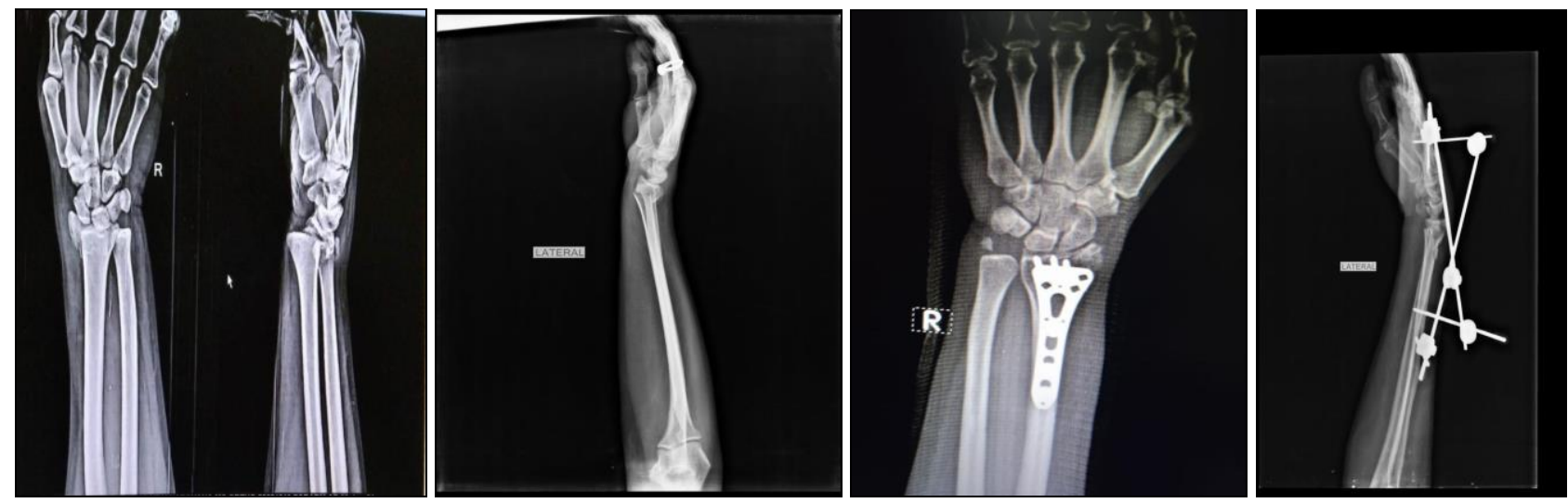

Fig 1: fracture of distal end of radius treated by external and internal fixation

\section{Discussion}

Present study has been conducted to evaluation of outcome of surgical management of unstable comminuted fracture of distal radius using external and internal fixation in our clinical conditions. During study period of four years, we enrolled 80 patients as per selection criteria and divided in to two groups have 40 patients each, one group were treated with external fixation and another treated with internal fixation. We have observed that mean age of patients was $41.35 \pm 12.38$ years in external fixation and $40.15 \pm 11.55$ years in internal fixation group and there was male predominance. Both groups are comparable to each other as it is not statistically significant. This finding corroborates with the studt of Mishra PK, Nagar M, Gaur SC, Gupta A et al., Madhu RG, Manikumar CJ et al. and Dr. Channareddy $\mathrm{H}$ et al. ${ }^{[9,10,11]}$.

In our study right side fracture was more common then left and fall from height was most common mechanism of injury in both groups. This finding is supported by the work of Havemann D, Busse FW et al. and Kulshrestha V, Roy T, Audige L et al. ${ }^{[12,13]}$. Both group of treatment are comparable 
to each other with respect to type of fracture and the mean of DASH score was16.24 \pm 4.62 in external fixation group and $14.65 \pm 3.98$ in internal fixation group which is less in internal fixation but is not statistically significant $(\mathrm{P}>.05)$. Wang $\mathrm{J}$, Yang Y, Ma J, Xing D, Zhu S, Ma B, Chen Y, Ma X et al. in its meta-analysis has reported that ORIF yields significantly better DASH scores at 3, 6 and 12 months after operation, comparing with $\mathrm{EF}$, and so does the volar plates; this finding supports our study ${ }^{[7] .}$ Xie X, Xie X, Qin H, Shen L, Zhang C has concluded in his meta- analysis that The pooled data showed that compared with EF, IF led to statistically significantly better Disabilities of the Arm, Shoulder, and Hand (DASH) scores at 12 months postoperatively, recovery of forearm supination at 3 months, and restoration of volar tilt and radial inclination that support our study ${ }^{[14]}$. Our study is also supported by the work of Antonio Abramo, Philippe Kopylov \& Magnus Tägil (2008) et al. ${ }^{[15]}$.

Chung KC, Malay S, Shauver MJ, Kim HM et al. has concluded that the rate for moderate complications was higher in the external fixation group which support our study. Anderson JT, Lucas GL, Buhr BR et al. has concluded that Postoperative complications following distal radius fractures treated with external fixation are common ${ }^{[16,17]}$. In present study we have found that infection was common in internal fixation group this finding corroborates with above mentioned studies.

Regarding functional outcome of patients with external and internal fixation using DASH (Disability of the Arm, shoulder and hand) Method, the outcome was better in internal fixation group this finding is supported by the work of Wright TW, Horodyski M, Smith DW et al. and) Phadnis J, Trompeter A, Gallagher K, Bradshaw L, Elliott DS, Newman KJ et al. ${ }^{[18,19]}$.

\section{Conclusion}

From present study we can conclude that fracture of distal end of radius is common fracture with male predominance. Injury is more common on right side and fall from height is common mode of injury. DASH score was less in internal fixation group. Post-operative infection was high in infernal fixation group. Functional outcome was better in outcome was better in internal fixation group.

\section{References}

1. Daid Johnson, Justin Lee, pectoral girdle and upper limb, Gray's anatomical basis of clinical practice Churchill Livingstone Elsevier publication $41^{\text {th }}$ edition 2008;(9)47:841.

2. Colles A. On the Fracture of the Carpal Extremity of the Radius. Edinb Med Surg J 1814;10(38):182-186. PMID: 30329360; PMCID: PMC5743240.

3. Pogue DJ, Vegas SF, Patterson RM, Peterson PD, Jenkins DK, Sweo TD, et al. Effects of distal radius malunion on wrist joint mechanics. J Hand Surg Am 1990;15:721-7.

4. Obert L, et al. Anatomy and biomechanics of distal radius fractures: a literature review. Chir Main 2012;31(6):287-297.

5. Meena S, Sharma P, Sambharia AK, Dawar A. Fractures of distal radius: an overview. J Family Med Prim Care 2014;3(4):325-32. doi: 10.4103/2249-4863.148101. PMID: 25657938; PMCID: PMC4311337.

6. Wei DH, Poolman RW, Bhandari M, Wolfe VM, Rosenwasser MP. External fixation versus internal fixation for unstable distal radius fractures: a systematic review and meta-analysis of comparative clinical trials. J
Orthop Trauma 2012;26(7):386-94.

doi: 10.1097/BOT.0b013e318225f63c. PMID: 22108259.

7. Wang J, Yang Y, Ma J, Xing D, Zhu S, Ma B, et al. Open reduction and internal fixation versus external fixation for unstable distal radial fractures: a meta-analysis. Orthop Traumatol Surg Res 2013;99(3):321-31.

doi: 10.1016/j.otsr.2012.11.018. Epub 2013 Mar 20. PMID: 23523527.

8. Hudak PL, Amadio PC, Bombardier C. The Upper Extremity Collaborative Group (UECG) Development of an upper extremity outcome measure: the DASH (disabilities of the arm, shoulder and hand) [corrected] Am J Ind Med 1996;29:602-608.

doi: 10.1002/(SICI)1097-0274(199606)29:6<602::AIDAJIM4>3.0.CO;2-L.

9. Mishra PK, Nagar M, Gaur SC, Gupta A. Morphometry of distal end radius in the Indian population: A radiological study. Indian J Orthop 2016;50(6):610-615. doi: 10.4103/0019-5413.193482. PMID: 27904215; PMCID: PMC5122255.

10. Madhu RG, Manikumar CJ. Functional evaluation of surgical fixation of distal radius fractures. J Evid Based Med Healthc 2020;7(48):2825-2830. DOI: $10.18410 /$ jebmh/2020/579

11. Dr. Channareddy H, Epidemiological profile of articular fractures of distal radius, National Journal of Clinical Orthopaedics 2018;2(3):17-20

12. Havemann D, Busse FW. Accident mechanisms and classifications in distal radius fractures. Langenbecks Arch Chir Suppl II Verh Dtsch Ges Chir 1990, 639-42.

13. Kulshrestha V, Roy T, Audige L. Dynamic vs static external fixation of distal radial fractures: A randomized study. Indian J Orthop 2011;45(6):527-34.

doi: 10.4103/0019-5413.87125. PMID: 22144746; PMCID: PMC3227357.

14. Xie X, Xie X, Qin H, Shen L, Zhang C. Comparison of internal and external fixation of distal radius fractures. Acta Orthop 2013;84(3):286-91.

doi: 10.3109/17453674.2013.792029. Epub 2013 Apr 18. PMID: 23594247; PMCID: PMC3715819.

15. Antonio Abramo, Philippe Kopylov, Magnus Tägil. Evaluation of a treatment protocol in distal radius fractures, Acta Orthopaedica 2008;79(3):376-385. DOI: $10.1080 / 17453670710015283$

16. Chung KC, Malay S, Shauver MJ, Kim HM. for the WRIST Group. Assessment of Distal Radius Fracture Complications Among Adults 60 Years or Older: A Secondary Analysis of the WRIST Randomized Clinical Trial. JAMA Netw Open 2019;2(1):e187053. doi:10.1001/jamanetworkopen.2018.7053

17. Anderson JT, Lucas GL, Buhr BR. Complications of treating distal radius fractures with external fixation: a community experience. Iowa Orthop J 2004;24:53-9. PMID: 15296207; PMCID: PMC1888410.

18. Wright TW, Horodyski M, Smith DW. Functional outcome of unstable distal radius fractures: ORIF with a volar fixed-angle tine plate versus external fixation. J Hand Surg Am 2005;30(2):289-99.

doi: 10.1016/j.jhsa.2004.11.014. Erratum in: J Hand Surg [Am] 2005;30(3):629. PMID: 15781351.

19. Phadnis J, Trompeter A, Gallagher K, Bradshaw L, Elliott DS, Newman KJ. Mid-term functional outcome after the internal fixation of distal radius fractures. J Orthop Surg Res 2012;7:4. doi: 10.1186/1749-799X-7-4. PMID: 22280557; PMCID: PMC3398340. 